\title{
Modeling of the Control System of Business Processes of Management of Region as an Economic Entity
}

\author{
Olena Bulatova \\ Economics and International Economic \\ Relations Department \\ Mariupol State University \\ Mariupol, Ukraine \\ olena_bulatova@yahoo.com
}

\author{
Tetiana Shabelnyk \\ Mathematical Methods and System \\ Analysis Department \\ Mariupol State University \\ Mariupol, Ukraine \\ tanya.shabelnik17@gmail.com \\ Tetyana Marena* \\ Economics and International Economic \\ Relations Department \\ Mariupol State University \\ Mariupol, Ukraine \\ t.marena@mdu.in.ua
}

\author{
Yurii Chentukov \\ Economics and International Economic \\ Relations Department \\ Mariupol State University \\ Mariupol, Ukraine \\ ie@mdu.in.ua
}

\begin{abstract}
The article is aimed at developing a model of a control system of business processes of management of the region as an economic entity. The relevance of such model is reasoned taking into account the necessity of ensuring efficient management of the region in terms of continuous dynamic changes in the external competitive environment and providing persistent improvement of the system of making deliberate management decisions for prevention of problem situations occurrence and their solution. The definition of the system of control of business processes of economic object management is offered. The model of control system of business processes of economic object management is developed, using the system analysis, optimization and adaptive management methods. Proposed model is an integrated, multifunctional system of management tools, which, due to considering the results of the implementation of management business processes and coordinating information flows, allows to improve efficiency of functioning of the region as a dynamic system that incorporates feedback.
\end{abstract}

Keywords - control system, model of control, management business process, region, economic entity, control points, modeling

\section{INTRODUCTION}

Performance of any economic entity is associated with the development and implementation of management decisions which quality and timeliness have an impact on the current and future efficiency and competitiveness of its functioning that is an influential factor of regions' development.

In the context of global integration, the process of regional development and governance has its own dialectic, which results in identification of the region as an actor in the system of international relations that is characterized by identity and institutional determination. The appropriate levels of the region are the following ones: local regional entities (the bottom-most level, which together with other entities of the kind can form a set of higher-order regions), microregions (arising from the development of joint production activities, the creation of foreign branches of companies, the formation of international territorial and industrial complexes), mesoregions (are characterized by formation of relevant economic areas in the structure of the national economy or small regions of neighboring countries, which existence is predetermined by integrity and sustainable nature of industrial and cooperative relations), macro-regions (are based on the formation of a single integrated economic complex which has its structure, governing bodies and requires a common macroeconomic policy), mega-regions (covering a set of relations arising in the world economy on the basis of development of integration cooperation between countries in a certain region, which results in the emergence of integration associations), meta-regions (are related to the formation of associations between countries belonging to certain continent). Identification of the appropriate levels of the region is necessary in terms of ensuring the governance and management of the group of countries, national economy, territorial communities, etc.

Current economic environment, due to instability and to some extent uncertainty, stipulates the use of effective management methods that are relevant to the level of development of modern economic entities as dynamic systems, in order to ensure the balanced formation of economic indicators. Ensuring effective management of region as an economic entity in terms of continuous dynamic changes in the external competitive environment requires persistent improvement of the system of making deliberated management decisions for prevention of problem situations occurrence and their solution.

Among the main tasks of optimal management of region as an economic entity, one can identify defining the most important characteristics of the states of an economic entity as a dynamic system having proper feedback and detecting deviations from optimal values in management business processes while implementing control functions [1]. In turn, 
they are aimed at comparing the actual results achieved by economic entity to the planned ones.

A quality system of permanent monitoring and control ensures efficient management feedback, allows identifying positive aspects of the performance of any economic entity in order to avoid crisis situations and inadequate management decisions that hinder its efficient functioning. Alongside it, problems of stabilization are being solved. They require solutions aimed at eliminating shortcomings and development problems and focused on improving economic entity efficiency due to changes in the main parameters of the management system by system transition from one state to another.

\section{ANALYSIS OF RESEARCH AND PROBLEM STATEMENT}

In actual studies, the region is defined as a complex phenomenon, which is expressed in several areas: territorial, reproductive, functional, political, etc. Recent studies highlight a growing role of regions as independent actors in the international economy [2], [3], [4]. Accordingly, in the international relations the importance of regions as modern economic entities is increasing. The spatial structure of the global economy has a complex and multilevel hierarchy, which is determined by the relevant levels of regions, namely: local regional entities, microregions, mesoregions, macroregions (or national regional entities), megaregions, metaregions, etc., which correspond to three main taxonomic regional levels: intrastate, national, supranational.

As a subsystem of the world economy, region is considered by international economics as a space that is formed by a set of countries of a certain region or continent of the world having a high degree of economic ties that arise on the basis of common interests, resources, level of productive forces development and nature of specialization, complementarity of trade, including the format of the integration union, which also acts as an economic entity.

Issues of control of business processes of an economic entity management were studied in the framework of different approaches (financial, system, internal) and were highlighted in the works of leading scientists [5], [6], [7]. In particular, these works are focused on theory and methodology of financial control [5]; internal control of economic activity of industrial enterprise [8]; the classifications problems of control types [6]; the problems of internal control development and their solutions at Ukrainian economic entities [7]; the methods of business processes control [9], [10], [11].

Alongside it, acknowledging the scientific and practical significance of the works of the above-mentioned researchers it should be noted that system elaborations on modeling of control functions of business processes of management of the region as an economic entity are not numerous and therefore require further studies.

The article is aimed at developing a model of a control system of business processes of management of the region as an economic entity, using the system analysis, optimization and adaptive management methods, which, due to considering the results of the implementation of management business processes and coordination of information flows, improves efficiency of an economic entity functioning.

\section{RESEARCH RESULTS}

Among the main requirements for a quality control system of an economic entity one can distinguish obtaining the following features: control efficiency, which is determined by the reduction of costs of control; identification of failures or deviations in the system of an economic entity management and their elimination; definition of control measures limits, determined by the legislative and regulatory frameworks and market environment.

The fulfillment of control functions of continuous management of the region as an economic entity is ensured by the process of checking the conformity of the economic entity's state to the optimum characteristics at time $t$ in order to adapt its management business processes to the current conditions of functioning and, as a consequence, balanced use of all kinds of resources.

The basic principle of functioning of the control system of an economic entity management is based on the formation of control points in management business processes. These points are a tool for accumulation of information data on efficiency of their activities and the determination of the compliance with the optimal values at all stages of the control process (preliminary, current and final). Control points identify changes in the implementation of management business processes and state deviations over a certain period of time for the development and implementation of qualitative management decisions [6]. This period of time varies depending on the dynamics of such changes.

The main reasons for changing the trajectory of implementing business processes of an economic entity management can be errors appearing during development and implementation of management decisions, deviation of external and internal factors, occurrence of additional reserves for improving the efficiency of decisions etc. Thus, control points work provides the processes of data collection and processing towards the dynamics of iteration of management business processes and evaluates the deviation of the results of their implementation. Such deviations arise as a result of changes in the values of the set of external destabilizing influences such as changes in the competitive environment, purchasing power of the population, legislative and regulatory frameworks, technological and environmental conditions, the system of social and cultural values, organizational and labor structure of entity, etc., and changes in the values of the set of internal influences associated with current situational factors.

The next important principle of the functioning of the control system of the region management is the adjustment of the trajectories of management business processes to the specified values as a result of the control points work to ensure making and implementing management decisions adequate to the current situation in the region.

Fig. 1 shows a scheme of setting the trajectory of the business process of an economic entity management to the defined optimal trajectory. According to the scheme (Figure 1), management business process (MBP) has $\left(t_{0}+\lambda\right)$ of consecutive stages. In each $i$ stage, a management decision $y_{i}(t)$ is generated which transfers the dynamic system from the state $S_{i}\left(t_{0}\right)$ to the state $S_{i}\left(t_{0}+i\right)$. 


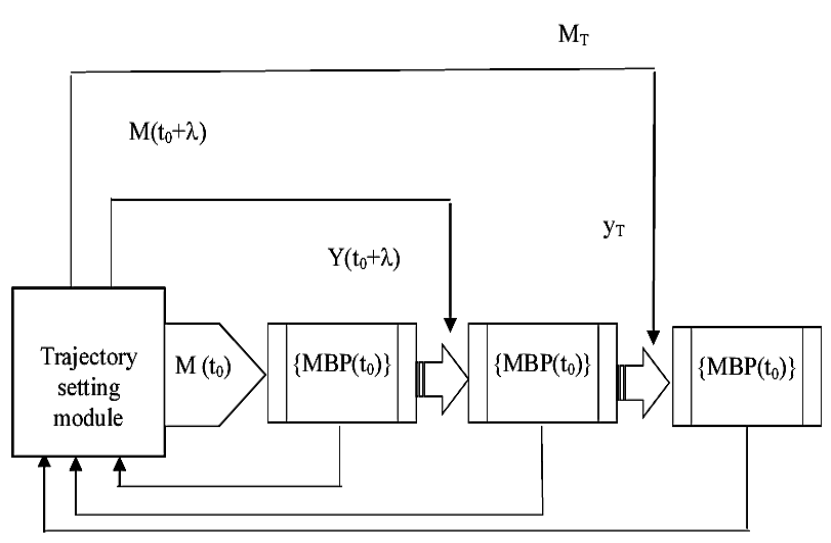

Fig. 1. Scheme of setting trajectory of management business process to optimal trajectory.

The transition function of the state of management business process is as follows:

$$
S_{i}(t)=f\left(t_{0},\left(t_{0}+i\right), S_{i}, q_{l}, y_{k}\right) \in \Psi,
$$

where $S_{i}(t)-i$-state of the business process of an economic entity management at time $t ; t_{0},\left(t_{0}+i\right)$ - the initial and current moment of time respectively, in which the dynamic economic entity is; $q_{l}$ - the value of $l$-parameter of the business process of an economic entity management; $y_{k}-$ the set of management impacts; $\Psi$ - the set of probable states of implementation of the business process of an economic entity management.

The business process of an economic entity management goes to the state $S_{i}(t)$, when at the initial time $t_{0}$ it was in the state $S_{0}\left(t_{0}\right) \in \Psi$ and was influenced by $y_{k}$.

The criterion of efficiency of setting the trajectory of management business process in the stage $\left(t_{0}+\lambda\right)$ can be defined as follows:

$$
\begin{aligned}
& B M P_{T}^{o p t}=\max _{y(t 0+\lambda)}\left(f\left(S\left(t_{0}+\lambda-1\right), y\left(t_{0}+\lambda\right)\right)+Z\left(t_{0}+\lambda+\right.\right. \\
& \left.1), S\left(t_{0}+\lambda\right)\right)
\end{aligned}
$$

Then, taking into account (2), the criterion of effectiveness of setting the trajectory of management business process in the final stage $T$ can be defined as follows:

$$
B M P_{T}^{o p t}=\max _{y(T)}(f(S(T-1), y(T)))
$$

After determining conditionally-optimal plan in accordance with the recurrent dependencies (2-3), unconditional optimization of the management process is carried out in the opposite direction and management decisions, which provide the maximum efficiency of the entire control system of the business process of the economic entity management, are formed. The setting module of trajectory $M$ of management business process movement generates a set of managerial impacts for each set-up period of the trajectory of implementation of the management business process over the time period $\left(t_{0}, T\right)$.
As a result of the specific nature of the process of an economic entity management, which is conditioned by great diversification of available goods and services, the variation in their prices and demand structure in the current market environment, there is currently no universal system of parameters for the formation of necessary and sufficient control points. However, it should be noted that introduction of control points in the control system of an economic entity management will ensure creation of such a subsystem of monitoring and optimization of management business processes that contributes to the continuity of their functioning, taking into account the constraints on all types of resources and minimization of information gaps between the results of the operations and managers who make decisions.

Taking into account the facts mentioned above, the following definition of the category of control system of an economic entity management is essential: the control system of an economic entity management is a complex dynamic system that identifies, prevents and corrects errors in management of an economic entity by timely detection of deviations in the implementation of its management business processes from the optimal values in case of control points functioning and implementation of appropriate management decisions.

Consequence 1 of definition: the structure of control points states and evaluates information data of efficiency indicators of business processes of an economic entity management in accordance with their implementation over a time period. Consequence 2 of definition: the set of control points of business processes of an economic entity management has constraints on the combination of their structural elements in order to avoid their unregulated growth. Consequence 3 of definition: business process of an economic entity management can be estimated with the help of control points, each of which has its own position in the algorithm of the management process.

Fig. 2 depicts graphic interpretation of implementation of the control system of an economic entity management.

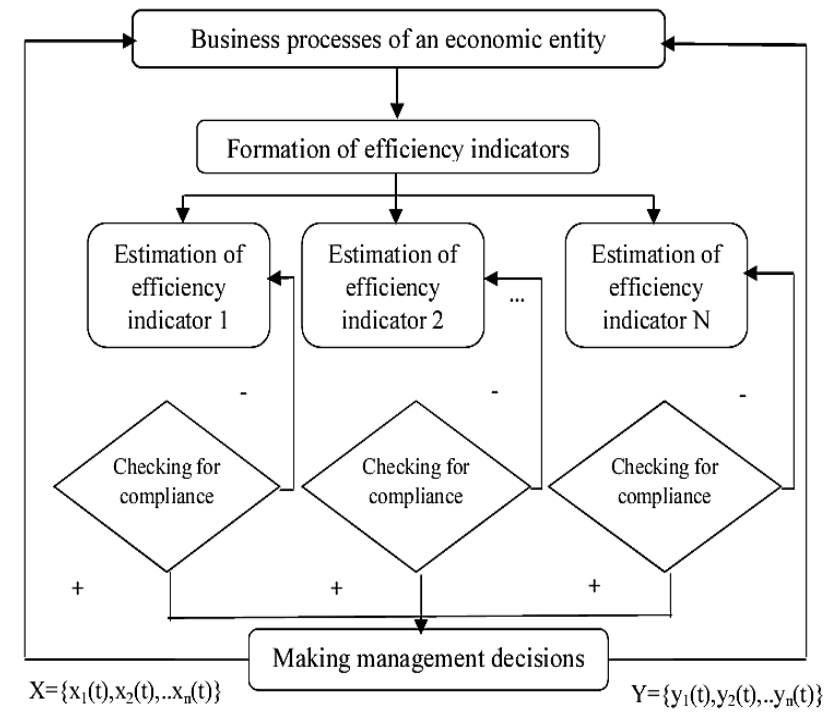

Fig. 2. Scheme of implementation of control system of an economic entity management. 
As one can see from Figure 2, the first stage of implementation of the control system of continuous management of an economic entity is formation of the efficiency indicators. After passing the partitioning element, decomposition of the control point into several connected points that move in parallel is made. The final stage of the work of each control point of business processes of an economic entity management is shifting to the element of fusion. At the exit of element of fusion a set of execution of restrictions on the values of the efficiency indicators $X=$ $\left\{x_{1}(t), x_{2}(t), \ldots, x_{n}(t)\right\}$ is generated. Such restrictions make the situation with uncontrolled growth of control points unacceptable. The set of impacts that manage $Y=\left\{y_{1}(t), y_{2}(t)\right.$, $\left.\ldots, y_{k}(t)\right\}$ is formed taking into account the set $X=\left\{x_{l}(t)\right.$, $\left.x_{2}(t), \ldots, x_{n}(t)\right\}$, and is a transition factor of management business process between its probable states $s_{i}(t)$.

Synthesis of the control function of business processes of an economic entity management is a procedure of determining the efficiency indicator and can be defined as follows [9]:

$$
\begin{gathered}
f\left(q_{i}(t), y_{k}(t), q_{i}\right) \rightarrow \text { extr, } \\
q_{i}(t)-q_{i}<\omega, \\
q_{i}(t), q_{i} \in \bar{Q},
\end{gathered}
$$

where $q_{i}(t)$ - degree of reaching by an economic entity the point aim of functioning at time $t ; q_{i}$ - point aim of the economic entity functioning; $\omega-$ value of deviation of characteristics of an economic entity functioning, which is set by management system; $\bar{Q}-$ area of the aim of an economic entity functioning.

The degree of reaching the point aim of functioning $q_{i}(t)$ by an economic entity depends on change in the trajectory of implementation of its management business processes under the influence of the set of factors $Y$.

The formation of an integral control system of business processes of an economic entity management is based on determining their efficiency by a certain indicator and comparing their values to the planned budget. The formation of efficiency indicators of business processes of an economic entity management depends on the defined control function according to (4-5), which can be oriented towards the achievement of the following optimization criteria [11]: shortening the time of implementation of management business process and control procedures fulfilled by management system; reduction of costs on implementing the full cycle of operational business processes that require the biggest spending; improving the performance of the full cycle of operational business processes that have revenue components; improving the quality of business management implementation; reducing the risk of management business process implementation.

In the framework of this study, the ways of formalizing defined optimization criteria of business processes of region's management are considered. To determine efficiency of business process of an economic entity management in terms of time indicator taking into account alternative variants of scenario, Dijkstra's Shortest Path First algorithm is used [12]. This method allows determining to what extent it is possible to reduce the length of management business process if the established term exceeds the critical one in terms of the negative components absence.

The following notations are introduced: $t_{h}$-duration of $h$-operation of business process of an economic entity management, $h=\overline{1, H} ; t_{h}{ }^{\min }$ - the minimum possible duration of $h$-operation of business process of an economic entity management, $h=\overline{1, H} ; t_{h}{ }^{\max }$ - the maximum possible duration of $h$-operation of business process of an economic entity management, $h=\overline{1, H} ; T_{h}{ }^{\text {min }}$ - the minimum possible term for the completion of $h$-operation of business process of an economic entity management, $h=\overline{1, H}$. One must take into consideration that $T_{h}^{\text {min }}=t_{h}^{\text {min }}+t_{h}$.

Then the optimal (minimum possible) duration of the business process of an economic entity management is calculated as follows:

$$
T^{\text {pt }}=\min \left\{T_{h}^{\min }\right\}
$$

But in dynamic economic systems, including regions, not only composition, interconnections and assessment of the duration of management business processes implementation are represented, but also probability of possible options for achieving the ultimate goal is estimated, by determining the probability of alternative ways of their implementation.

The duration of the management business process in this case acts as an accidental variable that can take any value over a given interval. Then, the optimal duration of the business process of an economic entity management $T^{\text {opt }}$ is estimated using the beta distribution as follows:

$$
f\left(T^{o p t}\right)=C\left(t_{h}^{\max }-T^{\text {opt }}\right)^{a}\left(T^{\text {opt }}-t_{h}^{\text {min }}\right)^{y} \text {, if } t_{h}^{\text {min }}<T^{o p t}<t_{h}^{\text {max }},
$$

where $a, y$ are integral parameters that determine the character of the distribution. $C$ - normalizing coefficients defined by the condition:

$$
\int_{t_{h}^{\min }}^{t_{h}^{\max }} f\left(T^{\text {opt }}\right) d t=1
$$

Condition (9) means that the sum of probabilities of all possible values $T^{o p t} \in\left[t_{h}{ }^{\min }, t_{h}{ }^{\max }\right]$ is equal to 1 , i.e. realization of only one variant is reliable. The values of $t_{h}{ }^{\min }$ and $t_{h}{ }^{\max }$ are based on managerial experience, expert method or statistical study methods.

Task (8) is performed under coordination of operations of management business processes, their control and elimination of certain procedures failures, which cause deviations from the established standards in order to minimize the budget expenditures of the region as economic entity.

From the point of view of quantitative assessment of management business processes implementation, which determines the final result of economic entity activities, control must be exercised over the operations that lead to obtaining economic results, namely, the operations for reducing the expenditures on managing mechanisms of implementing the full cycle of operational business processes and improving their efficiency. 
Thus, we define the ratio of the final result of the system activities to the total management costs as the quantitative indicator for efficiency of business processes of management of region as an economic entity. Then, estimation of efficiency of business processes of an economic entity management at the cost of $E^{V}$ can be determined by the following expression:

$$
E^{V}=\int_{t_{0}}^{T^{o p t}}\left(\sum_{h=1}^{H} \frac{\operatorname{Rez}_{h}(t)}{z_{h}^{v}(t)}\right) d t \rightarrow \max ,
$$

where $\operatorname{Re} z_{h}(t)$ is the final economic result of $h$-operation of the business process of an economic entity management, $h=\overline{1, H}, t \in T^{p p t} ; Z_{h}^{v}(t)$ - expenditures on management, control and optimization of $h$-operation of the business process of an economic entity management, $h=\overline{1, H}, t \in T^{p p t}$.

The indicator of the final economic result of management business processes can be determined with the help of region's financial and economic indicators. In order to determine the trend of the defined indicator of the final result of management business processes at time $t$, it is necessary to calculate the value of the derivative of the function $E^{V}(t)$ :

$$
\frac{d E^{V}(t)}{d t}=\frac{d\left(\int_{t_{0}}^{T^{o p t}}\left(\sum_{\hbar=1}^{H} \frac{R e z_{h}(t)}{Z_{h}^{V}(t)}\right) d t\right)}{d t} .
$$

If the derivative (11) exists at time $t$ and its value is negative, i.e.:

$$
\frac{d E^{V}(t)}{d t}<0
$$

then the value of the indicator of the final result of management business processes over the studied time period tends to decrease. So, the question is at what moment of time the actual value of the indicator will go below the critical value.

For quality control of efficiency of business processes of an economic entity management it is necessary to make a forecast of the system's behavior in the future period of time. For this purpose, according to statistical studies, the trend of the final result indicator of management business processes is formed:

$$
E^{V}=E_{\text {tend }}^{V}
$$

The control of the trend of the final result indicator of management business processes will provide a rapid response to the changes in the situation and will bring the system back to its normal functioning state. To avoid expanding the confidence interval when extrapolating the predicted function of the trend of the final result indicator of management business processes, limits for the size of the forecast error are set, i.e. the following ratio must be satisfied:

$$
\vartheta_{p}=\vartheta_{p} \cdot t_{\alpha} \leq \varepsilon
$$

where $\vartheta_{p}$ is forecast error; $\varepsilon$ - the value of the forecast error, which is given expertly; $t_{\alpha}-$ the value of Student's $t$ test; $\vartheta_{\sigma}-$ mean-squared deviation from the function.

With the function $E_{\text {tend }}^{V}(t)$, one can determine the moment of time $t$ before which the final result indicator of management business processes must reach the critical level $E^{V}{ }_{k r}(t)$, which can be specified expertly. Then, in order to determine this moment of time, it is necessary to find the intersection point of the function $E^{V}=E^{V}$ tend and the function $E^{V}=E_{k r}^{V}(t)$ i.e. the following system of equations must be solved:

$$
\left\{\begin{array}{c}
E^{V}=E_{\text {tend }}^{V}(t) \\
E^{V}=E_{k r}^{V}(t)
\end{array}\right.
$$

The solution to the system of equations (15) is the expression:

$$
\lim _{t \rightarrow t_{k r}} \sum_{h} \int_{t_{0}}^{T^{o p t}} E_{\text {tend }}^{V}(t) d t=E_{k r}^{V}(t)
$$

where $t_{k r}$ corresponds to the time of the critical value of the final result indicator of management business processes.

This means that at some point of time $t$ the curve will cross the line $E^{V}=E_{k r}^{V}(t)$ and at the next moment of time $(t$ $+1)$ the value of the efficiency indicator will be below the critical value $E_{k r}^{V}(t)$. Then, if $\left(t_{0}+i\right)$ is the current time, then introducing changes into the economic entity management system must be performed within the period of time $\left[\left(t_{0}+\right.\right.$ i), $T^{\text {opt }}$.

The optimal duration of a business process of an economic entity management must not exceed the period of time for reaching the critical level $E^{V}{ }_{k r}(t)$ :

$$
T^{\text {opt }}<T
$$

Limits imposed on the purpose function in solving the problem (10) can be represented as follows. Increase in expenditures on management, control and optimization of business processes of an economic entity management must not exceed the growth of the final economic result indicator:

$$
\frac{d^{2}\left(\operatorname{Rez}_{h}(t)\right)}{d t^{2}}>\frac{d^{2}\left(z_{h}^{v}(t)\right)}{d t^{2}}
$$

The average expenditures on management, control and optimization of business processes of an economic entity management $\overline{Z^{v}}$ must not exceed the given value of deviation of its functioning characteristics:

$$
\overline{Z^{v}}-q_{i}<\omega, q_{i} \in \bar{Q}
$$

Thus, as one can see from the problem (10-19), control of business processes of an economic entity management ensures a minimum of the average expenditures on management business process in each possible state $S_{i}(t)$. 
Formation of a high-quality control system of an economic entity management is impossible without taking into account the internal efficiency, which is best characterized by the level of deviations of the efficiency indicator of business processes of an economic entity management at cost $E^{V}$, depending on the variation of the final economic result of the business process of an economic entity management $R e z$ and expenditures on management, control and optimization $Z^{v}$.

The analysis of deviations of indicator $E^{V}$, depending on the changes of indicators $\operatorname{Rez}$ and $Z^{v}$ can be accomplished by using the algorithm of the sensitivity analysis method which implies, after formalizing the form of dependence between the indicators, determining the most probable values of the indicators and the ranges of their deviations. The next step of the algorithm is changing the values of incoming indicators and studying their effects on the final result. Then, when solving problem (10), it is necessary to add the following constraints to the purpose function. The coefficient of variation of the efficiency indicator of business processes of an economic entity management at cost $V\left(E^{V}\right)$ must not exceed the level of variation that is given by management system $\Delta$ :

$$
V\left(E^{V}\right) \leq \Delta
$$

Instability and uncertainty of the external environment caused by a change of a set of factors, such as fluctuations in demand and consumption, unexpected damage to equipment, business partners and competitors' activities, changes in exchange rates, changes in the legal framework and a number of other conditions, require formation of a qualitative control system of management of region as an economic entity, taking into account possible unfavorable events in the process of implementation of management business processes. So, there arises a probability of losing various types of resources, suffering additional operational and managerial losses, shortage of the planned revenue, etc.

In order to avoid the above mentioned situations, it is necessary to add to the function of purpose (10) restrictions on the degree of risk, which takes into account possible losses in the process of implementing management business process:

$$
\frac{d E_{\min }^{v}}{M\left(E_{\min }^{v}\right) d t} \geq 0,
$$

where $E_{\text {min }}^{v}$ - the minimum value of estimation of efficiency of business processes of an economic entity management; $M\left(E_{\text {min }}^{v}\right)$ - mathematical expectation of the minimum value of estimation of efficiency of business processes of an economic entity management.

Under condition (21), the risk is considered to be acceptable. Otherwise, the management business process is assessed as a critical one and requires correcting.

\section{CONCLUSIONS}

The given model of the control system of business processes of an economic entity management, developed for the purpose of region's management improvement, makes it possible to calculate the following parameters: optimal duration of the business process of an economic entity management, estimation of efficiency of business processes of region's management at the cost, the period of time during which changes to the economic entity management system are to be introduced.

The model is based on the methods of system analysis, optimization and adaptive management, and is an integrated, multifunctional system of management tools. It enables: to calculate the set of evaluative purpose orientation parameters which characterize features of the operations inside an economic entity's units; to generate a basis for developing management solutions adequate to current situation, for their further implementation into practice in order to adjust the level of economic efficiency of the region as an economic entity; to coordinate information flows among the units of the economic entity that ensure the continuity of its performance in the long run; to determine quantitative and qualitative results of management business processes by achieving the goals of an economic entity functioning; to take into account and minimize the risk of failure while implementing business processes of management of the region as an economic entity.

Further studies in this respect could be aimed at reasoning the choice of software for implementation of the control model of business processes of the region management and developing a methodology for its practical implementation.

\section{REFERENCES}

[1] B. N. Gerasimov, Management technology. Samara: Samara Institute of Business and Management, 2010. [in Russian].

[2] M. Castle, "Embedding regional actors in social and historical context: Australia - New Zealand integration and Asian-Pacific regionalism", Review of International Studies, vol. 44, no. 1, pp. 151173, 2018.

[3] M. Kahler, "Regional challenges to global governance", Global Policy, vol. 8, no. 1, pp. 97-100, 2017.

[4] A. J. Scott, and M. Storper, "Regions, globalization, development", Regional Studies, vol. 37, no. 6\&7, pp. 579-593, 2003.

[5] K. K. Arabyan, Theory and methodology of financial control. M: MESI, 2012. [in Russian].

[6] L. A. Majsigov, "Problems of classification of types of control", Econometric analysis: theory and practice, vol. 9, pp. 12-26, 2007. [in Russian].

[7] V. M. Yacenko, "Internal control at Ukrainian enterprises: problems of development and solutions", Accounting and auditing, vol. 11, pp. 3-7, 2010. [in Ukrainian].

[8] T. A. Khudyakova, "Principles for evaluating the effectiveness of the sustainability controlling system at the enterprise on the basis of the fuzzy sets theory", Actual Problems of Economics, vol. 12(174), pp. 444-450, 2015.

[9] O. V. Arefieva, and T. V. Lutska, Business processes of the services sector enterprises: factors, formation, competitiveness. K.: Ed. of European University, 2009. [in Ukrainian].

[10] V. S. Ponomarenko, S. V. Minuhin, and S. V. Znahur, The theory and practice of business process modeling. Kh.: Kharkiv National Economic University, 2013. [in Ukrainian].

[11] T. V. Shabelnyk, Marketing-oriented pharmaceutical company management: models and methods. Poltava: Poltava University of Economics and Trade, 2015. [in Ukrainian].

[12] E. W. Dijkstra, "A note on two problems in connexion with graphs", Springer Science+Business Media, vol. 1, pp. 269-271, 1959 